\title{
Management of Biliary Atresia: A Review
}

\author{
KHAN LAMIANAHID ${ }^{1}$, MD ROKONUZZAMAN $^{2}$, ASM BAZLUL KARIM ${ }^{3}$, \\ KANIZ FATEMA ${ }^{4}$, AZMERI SULTANA $^{5}$
}

\begin{abstract}
Biliary atresia (BA) is a rare neonatal disease of unknown etiology, where obstruction of the biliary tree causes severe cholestasis, leading to biliary cirrhosis and death in the first years of life, if the condition is left untreated. It is the most common cause of neonatal cholestasis and most common indication for liver transplantation in children. Biliary Atresia clinically presents with jaundice, pale stool, dark urine and hepatomegaly. The treatment of biliary atresia is surgical and is recommended as a sequence of, eventually, two interventions. During the first months of life a hepatoportoenterostomy (Kasai operation) should be performed, in order to restore the biliary flow to the intestine and lessen further damage to the liver. If this fails and/ or the disease progresses towards biliary cirrhosis and life-threatening complications, then liver transplantation is indicated. Age at surgery had a progressive and sustained deleterious effect on the results of the Kasai operation until adolescence. So early detection of biliary atresia is necessary for optimum management and overall survival of the patient.
\end{abstract}

\section{Introduction}

Biliary atresia (BA) is a progressive, idiopathic, fibroobliterative disease of the extrahepatic biliary tree that presents with biliary obstruction exclusively in the neonatal period. ${ }^{1}$ Biliary atresia (BA) is a rare neonatal disease which causes severe cholestasis and rapidly progressing biliary cirrhosis. It is the most frequent surgical cause of cholestatic jaundice in neonates. ${ }^{1}$ Biliary atresia is uniformly fatal within 1 to 2 years if left untreated. It is the most common indication for liver transplantation in children.

\section{Epidemiology}

As a birth defect in newborn infants, it has an occurrence rate of $1 / 10,000$ to $1 / 15,000$ cases in live births in the United States, ${ }^{2}$ with the most accurate prevalence recorded at $1 / 16,700$ in the British

1. Consultant, 500 beded Mugda General Hospital, Dhaka, Bangladesh.

2. Associate Professor, Department of Paediatric Gastroenterology and Nutrition, Bangabandhu Sheikh Mujib Medical University, Bangladesh.

3. Chairman, Department of Paediatric Gastroenterology and Nutrition, Bangabandhu Sheikh Mujib Medical University, Bangladesh.

4. Assistant Professor, Department of Paediatric Neurology, Bangabandhu Sheikh Mujib Medical University, Bangladesh.

5. Assistant Professor, Department of Paediatrics, ICH \& SSF Hospital, Mirpur, Dhaka, Bangladesh.
Isles. ${ }^{3,4}$ The disease is most common in East Asia with a frequency of $1 / 5,000 .{ }^{5}$ Reasons for this high incidence have not been described yet. Some analyses of time and space distribution of BA cases suggested seasonal variation and clustering of case ${ }^{6}$, but these observations were not confirmed in larger studies. ${ }^{7}$

\section{Types of Biliary Atresia}

Biliary atresia without any other anomalies or malformations - It is sometimes referred to as perinatal $B A$, and occurs in 70 to 85 percent of infants with BA. ${ }^{8,9}$ Typically, these children are born without jaundice, but within the first two months of life, jaundice develops and stools become progressively pale.

Biliary atresia in association with laterality malformations - This pattern is also known as Biliary Atresia Splenic Malformation (BASM) or "embryonal" biliary atresia, and occurs 10 to 15 percent of infants with BA. ${ }^{8-11}$ The laterality malformations include situs inversus, asplenia or polysplenia, malrotation, interrupted inferior vena cava, and cardiac anomalies. Data suggest that children with BASM have poorer outcomes compared to those with perinatal BA. ${ }^{10,11}$

Biliary atresia in association with other congenital malformations - This occurs in the remaining 5 to 10 percent of $B A$ cases and associated 
congenital malformations include intestinal atresia, imperforate anus, kidney anomalies and/or heart malformations ${ }^{8,12,13}$

\section{Etiopathogenesis}

Infection: Etiology and pathogenesis of biliary atresia are largely unknown. There have been many theories about etiopathogenesis such as Reovirus infection, congenital malformation, congenital CMV infection, and autoimmune theory. To date, a specific virus has not been implicated and investigations have failed to identify associations with several specific viral infections including cytomegalovirus, reovirus, and group C rotavirus. ${ }^{14-17}$ In a Norwegian study of 10 consecutive BA patients, eight of 10 children and one parental couple presented laboratory results suggestive of recent or persistent viral infection, four by CMV and five by EBV, with detection of CMV-DNA in two liver biopsies and of EBV-DNA in one, with no sign of viral infection being detected in a control group of 10 patients matched by age and tested by PCR in serum and viral antibodies. ${ }^{18}$

Toxins: The clustering of cases of BA is also consistent with the possibility of a toxin-mediated inflammatory response. The strongest evidence for this hypothesis comes from three reported outbreaks of BA in lambs in Australia in 1964, 1988, and 2007. ${ }^{19}$ A possible association with the gene GPC1 which encodes a glypican 1-a heparan sulfate proteoglycan has been reported. ${ }^{20}$ This gene is located on the long arm of chromosome 2 (2q37). This gene is involved in the regulation of the gene Hedgehog and also of inflammation. In addition to the association of mutations in the gene and the abnormally low levels of this protein in human cases, knock out mutants in zebra fish develop similar lesions in the liver. Hedgehog inhibitors ameliorate the features in the mutated fish and the addition of Hedgehog to normal fish produce lesions.

Immune dysregulation: Immune dysregulation, either as a primary disorder or as the result of infectious or genetic triggers, has been found in various studies. $^{21-23}$

\section{Diagnosis}

Clinical features: BA may be suspected prenatally, when a cystic structure is observed in the porta hepatis. ${ }^{24}$ The classic clinical triad of BA is constituted by (i) jaundice (conjugated, and persisting beyond two weeks of life), (ii) acholic (white) stools, dark urine, and (iii) hepatomegaly. All cases of neonatal jaundice lasting longer than 14 days must be explored in order to rule out BA or other causes of neonatal cholestasis. ${ }^{25-27}$

\section{Laboratory Studies:}

In cases of BA, biochemical liver function tests are typically those of cholestasis, with elevated levels of total and conjugated bilirubin, increased gammaglutamyl transpeptidase and alkaline phosphatase, and sometimes slightly higher than normal transaminases. $^{28}$

\section{Imaging Studies:}

Abdominal ultrasonography is the noninvasive imaging investigation when BA is suspected. It is done to exclude other anatomic causes of cholestasis (i.e., choledochal cyst). Infants with BA, the gallbladder is usually either absent or irregular in shape. The triangular cord sign is a triangular echogenic density seen just above the porta hepatis on US scan. Its presence is highly suggestive of biliary atresia. ${ }^{29}$ Approximately $20 \%$ of BA cases have a patent gallbladder.

Hepatobiliary scintigraphy using technetium-labeled iminodiacetic acid derivatives aims at offering a dynamic, objective assessment of both parenchymal liver function and biliary excretion. In BA this exam will reveal a lack of excretion of the radioisotope into the intestine; however, this can also be observed in any severe neonatal non-obstructive cholestasis. ${ }^{30}$

Magnetic Resonance Cholangio-pancreatography (MRCP) is increasingly performed in cases of neonatal cholestasis, as it allows for a visualization of the major biliary structures, hence for the exclusion of BA. ${ }^{30}$ In a Korean study the diagnosis of BA was made by MRCP based on the non-visualization of extra-hepatic bile ducts and excluded on the basis of the complete visualization of extra-hepatic bile ducts; accuracy was $98 \%$, with sensitivity and specificity of $100 \%$ and $96 \%$, respectively. ${ }^{31}$

\section{Invasive Studies:}

Liver biopsy should be done in all infants suspected for biliary atresia. Its aim is to identify histologic changes consistent with obstruction that may need surgical exploration. It also differentiate BA from other causes of intrahepatic cholestasis, which would not need surgical exploration. Biopsy findings that indicate 
another etiology include bile duct paucity (Alagille syndrome), PAS positive diastase resistant granules (consistent with alpha-one antitrypsin deficiency), loss of MDR3 staining (suggestive of PFIC3), or giant cell hepatitis without proliferation of ducts. The earliest histological changes associated with BA may be relatively nonspecific, and biopsies done too early may give false negative results. ${ }^{32}$ Nevertheless, cholangiography is the most definitive investigation to diagnose BA. The cholangiogram can be obtained percutaneously ${ }^{33}$, by laparoscopy ${ }^{34}$, via an open laparotomy, or through an endoscopic retrograde cholangiopancreatography (ERCP). ${ }^{35-37}$

\section{Management of Biliary Atresia}

The current management of BA patients is sequential and involves two steps: (1) Kasai hepato-portoenterostomy (HPE) in the neonatal period, in order to restore bile flow towards the intestine and preserve liver function as long as possible and (2) liver transplantation (LT), if no clearance of jaundice can be achieved through the Kasai operation or when complications of biliary cirrhosis appear later on.

The Kasai Hepatoportoenterostomy (HPE): It remains the preferred initial treatment, even though it is estimated that about $80 \%$ of patients with BA will ultimately need a liver transplantation. In a French study where 271 patients were analyzed, $23 \%$ were alive with their native liver twenty years after a Kasai procedure. ${ }^{38}$ Though, in the later in life most will need the transplantation, this procedure lowers morbidity and mortality. ${ }^{39}$ If biliary atresia (BA) is confirmed by cholangiogram, a Kasai procedure ( hepatoportoenterostomy [HPE] ) should be performed promptly. This operation is undertaken in the attempt to restore bile flow from the liver to the proximal small bowel. ${ }^{40}$ The procedure is to excise the entire obliterated biliary tree, transecting it at the level of the porta hepatis in order to expose microscopic but communicating biliary channels. A Roux loop is then created from the proximal jejunum and anastomosed to the cut surface. Restoration of biliary flow is then achieved, although the degree is variable and how it has been measured is controversial. ${ }^{41-43}$ Several prognostic factors of the Kasai operation have been related to the short-term results of this procedure. Among them are many that can not be altered, such as anatomy of the biliary remnant, ${ }^{44}$ histology of the liver, ${ }^{45-46}$ portal pressure at the time of Kasai operation, ${ }^{47}$ or association of BA with polysplenia (BA splenic malformation syndrome). ${ }^{48}$ Other prognostic factors of BA are related to the organization of care to these patients, and therefore are improvable: age at Kasai operation, accessibility to $L T$, and experience of the center in the management of patients with BA. ${ }^{49}$

Laparotomy versus Laparoscopy HPE: The HPE is usually performed via a transverse laparotomy but can also be achieved using laparoscopy ${ }^{50-51}$, in particular with robotics. ${ }^{52}$ Yet, recently discussions have emerged about the evidence based indication of the laparoscopic Kasai operation. In 2011, Ure et al. reported a prospective study that demonstrated that this approach is indeed technically feasible, but the study was stopped after inclusion of 12 infants subjected to a laparoscopic Kasai, due to a significant lower survival with the native liver compared to children treated by its laparotomic counterpart. ${ }^{53}$ Another study failed to detect any benefit of laparoscopic compared with conventional HPE, in particular no lower incidence of adhesion formation hence easier subsequent LT, one of the intended goals of the laparoscopic approach. ${ }^{54}$

If the Kasai operation succeeds, bile flow is restored, the stools become colored, and jaundice fades. Thus, the natural evolution of BA towards biliary cirrhosis is delayed or even, rarely, altogether prevented, so that the Kasai operation may help to postpone LT until late childhood, adolescence, or even adulthood. ${ }^{46}$

Postoperative Care: What is the best postoperative management after HPE remains un-established. Different drugs may be administered, but standardized protocols have not been defined prophylactic antibiotics to prevent cholangitis, ${ }^{55,56}$ barbiturate, cholestyramine and ursodeoxycholic acid to enhance bile flow ${ }^{57}$, and steroids to reduce inflammation might be beneficial. Glucocorticoids stimulate the transcription of genes coding for anti-inflammatory proteins ${ }^{58}$ and, additionally, steroids appear to have positive pharmacological actions on the bile flow. 59,60 Yet, the use of this category of drugs remains controversial. Postoperative steroids have been used empirically for many years, with a number of retrospective, uncontrolled reports. A recent randomized, double-blind, placebo-controlled trial of prednisolone after Kasai HPE (initial dose 2 mg/kg/ day) indicated a beneficial effect on the rate of reduction of bilirubin in the early postoperative period (specifically in infants less than 70 days old at surgery), but no reduction in the ultimate need for LT. 61 
Nutrition: Nutritional problems in BA are common and difficult to overcome. Poor nutrition is a significant clinical problem and is one of the most common indications for liver transplantation. To compensate for losses and catabolism, the expected protein needs are 3 to $4 \mathrm{~g} / \mathrm{kg} /$ day in infants and 2 to $3 \mathrm{~g} / \mathrm{kg} /$ day in children $^{62-64}$. High-energy supplements, such as glucose polymers (which provide 8 cal/teaspoon) or medium chain triglyceride oil (which provides $7.7 \mathrm{cal} /$ $\mathrm{mL}$ ), are used to fortify formula or solid foods. ${ }^{64}$ Deficiencies of fat-soluble vitamins are common in patients with BA. In a series of 29 patients with BA, serologic deficiencies of vitamins $A$ and $E$ and radiographic evidence of vitamin $D$ deficiency were reported despite establishment of bile flow by hepatoportoenterostomy. ${ }^{65}$ Vitamin deficiencies occur despite recommended supplementation and are particularly common among patients with residual cholestasis after Kasai HPE (serum bilirubin 2 mg/ dL). 66,67

Antibiotics: Ascending cholangitis is a common complication in patients with BA who have undergone a Kasai HPE (excluding post-surgical complications). The incidence of cholangitis in these patients is between 40 and 90 percent, with the majority of patients experiencing at least one episode prior to two years of age. Because cholangitis can be life threatening and may impact long- and short-term outcomes $^{68}$, most clinicians prescribe prophylactic antibiotics in the first year of life. Small non-randomized trials suggest that the benefits of antibiotic prophylaxis outweigh the risks of antibiotic resistance. ${ }^{69}$ In one series, infants treated with prophylactic antibiotics had half the rate of cholangitis as compared with infants in a historical control group. Either trimethoprim/ sulfamethoxazole ( $4 \mathrm{mg} / \mathrm{kg} /$ day trimethoprim and 20 $\mathrm{mg} / \mathrm{kg} /$ day sulfamethoxazole, divided twice daily) or neomycin (25 mg/kg/day divided four times daily) appear to be equally effective in decreasing the incidence of cholangitis. ${ }^{70}$

Sclerotherapy or banding: The chronic hepatobiliary inflammation characteristic of BA leads to progressive biliary cirrhosis. Biliary cirrhosis causes portal hypertension, which can lead to variceal bleeding and ascites. In a registry study of 163 children with BA in North America who had not undergone liver transplantation (average age 9.2 years), half had definite portal hypertension. ${ }^{71}$ If portal hypertension leads to variceal bleeding, this complication is often controlled with sclerotherapy or banding.

\section{Liver Transplantation (LT) for Biliary Atresia}

If the Kasai operation is not successful, that is, no restoration of bile flow is achieved, and/or medical complications of biliary cirrhosis appear, even if jaundice has subsided, liver transplantation (LT) is indicated. Most transplantations for BA patients are performed in the first or second year of life. BA represents about half of the indications for LT in childhood. ${ }^{72}$ LT should not be deferred too long once it becomes apparent that it will be required, since timing of LT not only affects survival, but may also influence neurodevelopmental outcome. ${ }^{73}$ Nutritional support before transplantation and, reciprocally, performance of transplantation before malnutrition develops may reduce developmental delays. ${ }^{74}$ There are two sources for a liver graft. (1) Cadaveric donor: the graft usually derives from an adult donor, and the left lobe (segments 2 and 3 ) or the left liver (segments 2,3 , and 4) is used after in situ or ex situ splitting of the whole liver. Pediatric donors are much less frequent, but in those cases the whole liver can be transplanted. (2) Living-related donor: usually the donor is a close relative, in most cases one of the parents. A left lobectomy is generally performed to transplant segments 2 and 3 . Morbidity of the lobectomy performed in the donor is not negligible, reaching $10 \% .{ }^{75}$ The goal of the LT is to offer a normal life to these children, allowing for normal physical, intellectual, psychological, sexual, and social development. ${ }^{76}$

\section{Prognosis}

Although long-term prognosis for biliary atresia patients is variable, the complementary and sequential approach of HPE and liver transplantation affords longterm survival, with upwards of 90 percent of BA patients surviving into adulthood. ${ }^{77,78}$ Survival without transplantation with native liver ranges from 30 to 55 percent at five years, 30 to 40 percent at 10 years, and 20 to 40 percent at 20 years. ${ }^{78}$ Surgical success is dependent on the expertise of the center and surgeon. Although controversial, it appears that a center that performs at least five Kasai procedures per year has a better success rate, as measured by 5- or 10-year long-term survival with the native liver. ${ }^{49}$ Another surgical factor is anatomic pattern of biliary atresia identified at time of Kasai hepatoportoenterostomy. Children born without atresia at the porta hepatis (Ohi classification 1) have the lowest risk of death or transplantation by two years of age. ${ }^{79}$ Among all variables, serum bilirubin post HPE appears 
to be the most predictive biomarker of outcome. Data suggest that the serum total bilirubin level measured three months after Kasai HPE is predictive of native liver survival. Among patients with bilirubin $<2 \mathrm{mg} / \mathrm{dL}$ three months post Kasai HPE, two year survival without transplantation was 84 percent. Among patients with bilirubin $6 \mathrm{mg} / \mathrm{dL}$ three months post Kasai HPE, survival without transplantation was only 16 percent. $^{8}$

\section{Conclusion}

The future for children with biliary atresia depends on better understanding of the aetiopathogenesis, optimizing referral, surgical management and problem specific postoperative care. Age at surgery had a progressive and sustained deleterious effect on the results of the Kasai operation until adolescence. So early detection of BA is necessary for optimum management and overall survival of the patient. If a BA child can be maintained in good health for longer with its own liver, that is, if LT can be delayed after infancy and early childhood, it lessens the risks of the LT procedure itself.

\section{References}

1. Haber BA, Russo P. Biliary atresia. Gastroenterol Clin North Am 2003; 32:891-911.

2. Cauduro SM. Extrahepatic biliary atresia: diagnostic methods. J Pediatr (Rio J) 2003;79:107-14.

3. McKiernan PJ, Baker AJ, Kelly DA. The frequency and outcome of biliary atresia in the UK and Ireland. Lancet 2000;355: 25-29.

4. Hartley JL, Davenport M, Kelly DA. Biliary atresia. Lancet 2009; 374: 1704-13.

5. Leyva-Vega M, Gerfen J, Thiel BD, Jurkiewicz D, Rand EB, Pawlowska J et al. Genomic alterations in biliary atresia suggest region of potential disease susceptibility in 2q37.3. Am J Med Genet 2010; 152: 886-895.

6. Yoon PW, Bresee JS, Olney RS, James LM, Khoury MJ. Epidemiology of biliary atresia: a population-based study. Pediatrics 1997;99:376-382.

7. Davenport M, Dhawan A, Yoon P, Bresee JS, Olney RS, Khoury MJ. Epidemiologic study of infants with biliary atresia. Pediatrics 1998;101:729-730.
8. Shneider BL, Brown MB, Haber B, Whitington PF, Schwarz K, Squires R, et al. A multicenter study of the outcome of biliary atresia in the United States, 1997 to 2000. J Pediatr 2006; 148:467-474.

9. Schwarz KB, Haber BH, Rosenthal P, Mack $\mathrm{CL}$, Moore J, Bove K, et al. Extrahepatic anomalies in infants with biliary atresia: results of a large prospective North American multicenter study. Hepatology 2013; 58:1724-31.

10. Davenport M, Savage M, Mowat AP, Howard ER. Biliary atresia splenic malformation syndrome: an etiologic and prognostic subgroup. Surgery 1993;113:662-668.

11. Davenport M, Tizzard SA, Underhill J, MieliVergani G, Portmann B, Hadziæ N. The biliary atresia splenic malformation syndrome: a 28-year single-center retrospective study. J Pediatr 2006; 149:393-400.

12. DeMatos V, Erlichman J, Russo PA, Haber BA. Does "cystic" biliary atresia represent a distinct clinical and etiological subgroup? A series of three cases. Pediatr Dev Pathol 2005; 8:725-731.

13. Muise AM, Turner D, Wine E, Kim P, Marcon M, Ling CC. Biliary atresia with choledochal cyst: implications for classification. Clin Gastroenterol Hepatol 2006;4: 1411-1414.

14. Bates MD, Bucuvalas JC, Alonso MH, Ryckman FC. Biliary atresia: pathogenesis and treatment. Semin Liver Dis 1998; 18:281-293.

15. Hart MH, Kaufman SS, Vanderhoof JA, Erdman S, Linder J, Markin RS, et al. Neonatal hepatitis and extrahepatic biliary atresia associated with cytomegalovirus infection in twins. Am J Dis Child 1991; 145:302-305.

16. Shivakumar $P$, Campbell KM, Sabla GE, Miethke A, Tiao G, McNeal MM, et al. Obstruction of extrahepatic bile ducts by lymphocytes is regulated by IFN-gamma in experimental biliary atresia. J Clin Invest 2004; 114:322-329.

17. Tarr PI, Haas JE, Christie DL. Biliary atresia, cytomegalovirus, and age at referral. Pediatrics 1996; 97:828-831.

18. Fjær RB, Bruu AL, Nordbø SA. Extrahepatic bile duct atresia and viral involvement. Pediatric Transplantation 2005; 9:68-73. 
19. Harper P, Plant JW, Unger DB. Congenital biliary atresia and jaundice in lambs and calves. Aust Vet J 1990; 67:18-22.

20. Cui S, Leyva-Vega M, Tsai EA, Eauclaire SF, Glessner JT, Hakonarson $\mathrm{H}$, et al. Evidence from human and zebrafish that GPC1 is a biliary atresia susceptibility gene. Gastroenterology 2013;144:1107-1115.

21. Muraji T, Hosaka N, Irie N, Yoshida M, Imai $\mathrm{Y}$, Tanaka K, et al. Maternal microchimerism in underlying pathogenesis of biliary atresia: quantification and phenotypes of maternal cells in the liver. Pediatrics 2008; 121:517-521.

22. Bezerra JA, Tiao G,Ryckman FC, Alonso M, Sabla GE, Shneider B, et al. Genetic induction of proinflammatory immunity in children with biliary atresia. Lancet 2002; 360:1653-1659.

23. Shih $\mathrm{HH}$, Lin TM, Chuang $\mathrm{JH}$, Eng $\mathrm{HL}$, Juo SH, Huang FC, et al. Promoter polymorphism of the CD14 endotoxin receptor gene is associated with biliary atresia and idiopathic neonatal cholestasis. Pediatrics 2005; 116:437-441.

24. Redkar R, Davenport M, Howard ER. Antenatal diagnosis of congenital anomalies of the biliary tract. Journal of Pediatric Surgery 1998;33:700704.

25. Emerick KM, Whitington PF. Neonatal liver disease. Pediatric Annals 2006;35:280-286.

26. Bernard O. Plea for early diagnosis of biliary tract atresia twelve errors to avoid. Archives of Pediatrics 1995;2:937-939.

27. Mieli-Vergani G, Portman B, Howard ER, Mowat AP. Late referral for biliary atresia-missed opportunities for effective surgery. Lancet 1989;1:421-423.

28. Stylianos S, Hick BA. Abdominal Trauma. In: Oldham K, Colombani P, Foglia R, Skinner MA, eds. Principles and Practice of Pediatric Surgery, Lippincott Williams \& Wilkins, 2005:431-446.

29. Park WH, Choi SO, Lee HJ, Kim SP, Zeon SK Lee SK. A new diagnostic approach to biliary atresia with emphasis on the ultrasonographic triangular cord sign: comparison of ultrasonography, hepatobiliary scintigraphy, and liver needle biopsy in the evaluation of infantile cholestasis. J Pediatr Surg 1997; 32:1555-1559.
30. Takaya J, Nakano S, Imai Y, Fujii Y, Kaneko K. Usefulness of magnetic resonance cholangiopancreatography in biliary structures in infants: a four-case report. European Journal of Pediatrics 2007; 166:211-214.

31. Han SJ, Kim MJ, Han A, Chung KS, Yoon CS, Kim D, et al. Magnetic resonance cholangiography for the diagnosis of biliary atresia. Journal of Pediatric Surgery 2002; 37:599-604.

32. Azar G, Beneck D, Lane B, Markowitz J, Daum $F$, Kahn E. Atypical morphologic presentation of biliary atresia and value of serial liver biopsies. J Pediatr Gastroenterol Nutr 2002;34:212-215.

33. Nwomeh BC, Caniano DA, Hogan M. Definitive exclusion of biliary atresia in infants with cholestatic jaundice: the role of percutaneous cholecysto-cholangiography. Pediatric Surgery International 2007;23:845-849.

34. Okazaki T, Miyano G, Yamataka A. Kobayashi $\mathrm{H}$, Koga, H, Lane, GJ, et al. Diagnostic laparoscopy-assisted cholangiography in infants with prolonged jaundice. Pediatric Surgery International 2006;22:140-143.

35. linuma $Y$, Narisawa R, Iwafuchi M, Uchiyama M, Naito M, Yagi M, et al. The role of endoscopic retrograde cholangiopancreatography in infants with cholestasis. Journal of Pediatric Surgery 2000;35:545-549.

36. Ohnuma N, Takahashi H, Tanabe M, Yoshida H, Iwai J. The role of ERCP in biliary atresia. Gastrointestinal Endoscopy 1997;45:365-370.

37. Shteyer E, Wengrower D, Benuri-Silbiger I, Gozal D, Wilschanski M, Goldin E. Endoscopic retrograde cholangiopancreatography in neonatal cholestasis. Journal of Pediatric Gastroenterology and Nutrition 2012;55: 142145.

38. Lykavieris P, Chardot C, Sokhn M, Gauthier F, Valayer J, Bernard O. Outcome in adulthood of biliary atresia: a study of 63 patients who survived for over 20 years with their native liver. Hepatology 2005;41:366-371.

39. Carceller A, Blanchard H, Alvarez F, St-Vil D, Bensoussan AL, Di Lorenzo M. Past and future of biliary atresia. Journal of Pediatric Surgery 2000;35:717-720. 
40. Davenport M, Ure BM, Petersen C, Kobayashi $\mathrm{H}$. Surgery for biliary atresia -is there a European consensus? Eur J Pediatr Surg 2007; 17:180183.

41. Serinet MO, Broue P,Jacquemin E, Lachaux A, Sarles J, Gottrand F, et al.Management of patients with biliary atresia in France: results of a decentralized policy 1986-2002. Hepatology 2006;44:75-84.

42. Nio M, Ohi R, Miyano T, Saeki M, Shiraki K, Tanaka K;. Five- and 10-year survival rates after surgery for biliary atresia: a report from the Japanese Biliary Atresia Registry. J Pediatr Surg 2003;38:997-1000.

43. Chardot C, Carton M, Spire-Bendelac N, Le Pommelet C, Golmard JL, Auvert B. Prognosis of biliary atresia in the era of liver transplantation: French national study from 1986 to 1996. Hepatology 1999;30:606-611.

44. Wildhaber B, Coran AG, Drongowski RA, Hirschl RB, Geiger JD, Lelli JL, et al. The Kasai portoenterostomy for biliary atresia: a review of 27-year experience with 81 patients. J Pediatr Surg 2003;38:1480-1485.

45. Shteyer E, Ramm GA, Xu C, White FV, Shepherd RW. Outcome after portoenterostomy in biliary atresia: pivotal role of degree of liver fibrosis and intensity of stellate cell activation. $\mathrm{J}$ Pediatr Gastroenterol Nutr 2006;42:93-99.

46. Schweizer P, Lunzmann K. Extrahepatic bile duct atresia: how efficient is the hepatoportoenterostomy? Eur J Pediatr Surg. 1998;8: 150-154.

47. Duche' M, Fabre M, Kretzschmar B, Serinet MO, Gauthier F, Chardot C. Prognostic value of portal pressure at the time of Kasai operation in patients with biliary atresia. J Pediatr Gastroenterol Nutr 2006;43:640-645.

48. Karrer FM, Lilly JR, Stewart BA, Hall RJ. Biliary atresia registry,1976 to 1989. J Pediatr Surg. 1990;25:1076-1080.

49. Davenport M, De Ville de Goyet J, Stringer MD, Mieli-Vergani G, Kelly DA, McClean P, et al. Seamless management of biliary atresia in England and Wales (1999-2002) Lancet. 2004;363:1354-1357.
50. Ayuso L, Vila-Carb JJ, Lluna J, Hern'andez E, Marco A. Laparoscopic Kasai portoenterostom: present and future of biliary atresia treatment," Cirug'ýa Pedi' atrica, 2008;21:23-26.

51. Esteves E, Neto EC, Neto MO, Devanir J, Pereira RE. Laparoscopic Kasai portoenterostomy for biliary atresia. Pediatric Surgery International 2002;18:737-740.

52. Dutta S, Woo R, Albanese CT. Minimal access portoenterostomy: advantages and disadvantages of standard laparoscopic and robotic techniques. Journal of Laparoendoscopic and Advanced Surgical Techniques 2007;17:258264.

53. Ure BM, Kuebler JF, Schukfeh N, Engelmann $\mathrm{C}$, Dingemann J, Petersen C. Survival with the native liver after laparoscopic versus conventional kasai portoenterostomy in infants with biliary atresia: a prospective trial. Annals of Surgery 2011;253:826-830.

54. von Sochaczewski CO, Petersen C, Ure BM, Osthaus A, Schubert KP, Becker T, et al. Laparoscopic versus conventional Kasai portoenterostomy does not facilitate subsequent liver transplantation in infants with biliary atresia. Journal of Laparoendoscopic \& Advanced Surgical Techniques 2012;22:408-411.

55. Bu LN, Chen HL, Chang CJ, Ni YH, Hsu HY, Lai $\mathrm{HS}$, et al. Prophylactic oral antibiotics in prevention of recurrent cholangitis after the Kasai portoenterostomy. Journal of Pediatric Surgery 2003;38: 590-593.

56. Kelly DA, Davenport M. Current management of biliary atresia. Archives of Disease in Childhood 2007;92:1132-1135.

57. Vajro $\mathrm{P}$, Couturier M, Lemonnier F, Odievre M. Effects of postoperative cholestyramine and Phenobarbital administration on bile flow restoration in infants with extrahepatic biliary atresia. Journal of Pediatric Surgery 1986;21: 362-365.

58. Elenkov IJ. Glucocorticoids and the Th1/Th2 balance. Annals of the New York Academy of Sciences 2004;1024:138-146.

59. Miner Jr PB, Gaito JM. Bile flow in response to pharmacologic agents. Hepatic DNA as a 
reference standard. Biochemical Pharmacology 1979;28:1063-1066.

60. Tatekawa Y, Muraji T, Tsugawa C. Glucocorticoid receptor á expression in the intrahepatic biliary epithelium and adjuvant steroid therapy in infants with biliary atresia. Journal of Pediatric Surgery 2005;40:1574-1580.

61. Davenport M, Stringer MD, Tizzard SA, McClean P, Mieli-Vergani G, Hadzic N. Randomized, doubleblind, placebo-controlled trial of corticosteroids after Kasai portoenterostomy for biliary atresia. Hepatology 2007;46:1821-1827.

62. FeranchakAP, Sokol R. Medical and nutritional management of cholestasis in infants and children. In: Suchy FJ, Sokol R, Balistreri W (Eds). Liver Disease in Children, Cambridge University Press, 2007:190.

63. Novy MA, Schwarz KB. Nutritional considerations and management of the child with liver disease. Nutrition 1997; 13:177-184.

64. Pierro A, Koletzko B, Carnielli V, Superine RA, Roberts EA, Filler RM, et al. Resting energy expenditure is increased in infants and children with extrahepatic biliary atresia. J Pediatr Surg 1989; 24:534-538.

65. Andrews WS, Pau CM, Chase HP, Foley LC, Lilly JR. Fat soluble vitamin deficiency in biliary atresia. J Pediatr Surg 1981; 16:284-290.

66. Shneider B, Abel R, Raghunathan T. A prospective multi-centered investigation of vitamin supplementation in infants with biliary atresia: Interim analysis from the biliary atresia research consortium (BARC). Hepatology 2009;50:631A632A.

67. Shneider BL, Magee JC, Bezerra JA, Haber B, Karpen SJ, Raghunathan T, et al. Efficacy of fatsoluble vitamin supplementation in infants with biliary atresia. Pediatrics 2012; 130:e607-614.

68. Luo Y, Zheng S. Current concept about postoperative cholangitis in biliary atresia. World J Pediatr 2008; 4:14-19.

69. Bu LN, Chen HL, Chang CJ, Ni YH, Hsu HY, Lai $\mathrm{HS}$, et al. Prophylactic oral antibiotics in prevention of recurrent cholangitis after the Kasai portoenterostomy. J Pediatr Surg 2003;38: 590-593.
70. Ernest van Heurn LW, Saing H, Tam PK. Cholangitis after hepatic portoenterostomy for biliary atresia: a multivariate analysis of risk factors. J Pediatr 2003; 142:566-571.

71. Shneider BL, Abel B, Haber B, Karpen SJ, Magee JC, Romero R, et al. Portal hypertension in children and young adults with biliary atresia. J Pediatr Gastroenterol Nutr 2012; 55:567-573.

72. Cox KL, Berquist WE, Castillo RO. Paediatric liver transplantation: indications, timing and medical complications. Journal of Gastroenterology and Hepatology 1999;14: S61-S66.

73. Wayman KI, Cox KL, Esquivel CO. Neurodevelopmental outcome of young children with extrahepatic biliary atresia 1 year after liver transplantation. Journal of Pediatrics 1997;131:894-898.

74. Fujita S, Kim ID, Uryuhara K, Asonuma K, Egawa $\mathrm{H}$, Kiuchi $\mathrm{T}$, et al. Hepatic grafts from live donors: donor morbidity for 470 cases of live donation. Transplant International 2000;13:333339.

75. Umeshita K, Fujiwara K, Kiyosawa K, Makuuchi M, Satomi S, Sugimachi K, et al. Operative morbidity of living liver donors in Japan. Lancet 2003;362:687-690.

76. Bucuvalas JC, Campbell KM, Cole CR, Guthery SL. Outcomes after liver transplantation: keep the end in mind. Journal of Pediatric Gastroenterology and Nutrition 2006;1:S41-S48.

77. Wildhaber BE, Majno P, Mayr J, Zachariou Z, Hohlfeld J, Schwoebel M, et al. Biliary atresia: Swiss national study, 1994-2004. J Pediatr Gastroenterol Nutr 2008; 46:299-307.

78. Chardot C, Buet C, Serinet MO, Golmard JL, Lachaux A, Roquelaure B, et al. Improving outcomes of biliary atresia: French national series 1986-2009. J Hepatol 2013; 58:1209-1217.

79. Superina R, Magee JC, Brandt ML, Healey PJ, Tiao G, Ryckman F, et al. The anatomic pattern of biliary atresia identified at time of Kasai hepatoportoenterostomy and early postoperative clearance of jaundice are significant predictors of transplant-free survival. Ann Surg 2011; 254:577-585. 